\title{
The Mediating Role of Sales Performance in the Effect of Antecedents on Sales Force Satisfaction: In the Case of Top Three Chain Retail Stores Operating in Ethiopia
}

\author{
Getie Andualem Imiru ${ }^{1}$ \\ ${ }^{1}$ School of Commerce, Addis Ababa University, Addis Ababa, Ethiopia \\ Correspondence: Getie Andualem Imiru, School of Commerce, Addis Ababa University, Addis Ababa, Ethiopia.
}

Received: January 24, 2018 Accepted: February 19, $2018 \quad$ Online Published: February 27, 2018

doi:10.5539/ijms.v10n1p145 URL: https://doi.org/10.5539/ijms.v10n1p145

\begin{abstract}
The objective of this study is to investigate the effect of antecedent variables on salesforce Job satisfaction mediated by salesforce performance. Data were gathered using a structured questionnaire from top three chain retail stores engaged in retailing business operating in Ethiopia. Although a total of 450 questionnaires were distributed to sales persons of these companies, 380 questionnaires were returned and used at the end of the data collection process, which gave the response rate of 84 per cent. The ability, effort, self-efficacy, and job core characteristics have a significant Pearson correlation of $0.493,0.105,0.288$, and 0.391 respectively at 0.01 confidence interval with sales performance. On the other hand, five constructs of the study ability, effort, self-efficacy, fixed compensation, and job core characteristics influenced sales performance significantly at $95 \%$ confidence interval with a sig. level of $0.000,0.004,0.002,0.000$, and 0.000 respectively. The result of the study indicated that six variables which are ability, effort, self-efficacy, fixed compensation, job core characteristics, and sales performance influenced job satisfaction significantly at $95 \%$ confidence interval with a sig. level of 0.000 for all variables.
\end{abstract}

Keywords: chain retail stores, salesperson performance, salesperson satisfaction, Ethiopia

\section{Introduction}

The study report is organized into six sections: Firstly, a brief overview of the retail chain stores in the country in general and the capital city in particular is highlighted; secondly, research questions were raised., Thirdly, objective of the study is also addressed. Fourthly, scope of the study is highlighted. Fifthly, Key areas in which the present study extends the previous literature on the sales persons performance and job satisfaction are highlighted. Sixthly, a broad conceptual framework is operationalized into a testable model, and research hypotheses are developed; seventhly, the design of the study and the methodological procedures are described; Eighthly, Result and discussion containing descriptive, correlation analysis, regression analysis and path analysis has been articulated. Ninthly, conclusion drawn from the study is highlighted. Finally, Implication of the study and future area of research has been Proposed.

\section{The Retail Sector in Ethiopia}

Over the last decade, Ethiopia has seen a surge in the number of grocery stores opening in the capital city, Addis Ababa as well as in other commercial cities of Ethiopia. This growing trend, which is expected to continue into the future, is primarily attributed to the country's double-digit growth over the last decade, urbanization, and the expanding population of Addis Ababa, the country's capital. Increased economic prosperity has translated into more disposable income that can be used for local and imported foods, including those outside the traditional Ethiopian diet. In addition, the presence of a sizeable expat and diaspora community is contributing to increased demand for certain imported foods, especially Western and Asian products.

There is an estimated five million people living in the ever -expanding and developing capital. As Addis Ababa grows, there is an increasing share of city dwellers that are opting to live in condominiums where they are unable to cook traditional foods, like the traditional fermented, flatbread, called injera, in their indoor kitchens or butcher animals in their backyards. As a consequence, more and more urban, middle -class consumers are turning to grocery stores, mini-marts, and neighborhood kiosks to satisfy some of the food and beverage demand. In response to this growing and anticipated future demand, the number of grocery stores has skyrocketed in recent years. Eight 
major supermarket chains, with a total of 21 stores, are open across Addis Ababa. The major food retail stores -Shoa, Fantu, Safeway, Friendship, Bambis, All -Mart, Novis, and Loyal -supply a wide array of products, most of which are imported foods and beverages. Sagaci Research, a market intelligence firm dedicated to African markets, tried to study Ethiopia's retail market potential. According to Sagaci, modern retailing business in Addis Ababa, is in early stages of development when compared to other sub-Saharan African countries. Eight modern retailers are operating 21 stores who represent $0.5 \%$ of total grocery spending in the country. All modern retailers in Addis Ababa are mid-sized local companies, operating medium-sized stores with no single store being larger than $1,500 \mathrm{sqm}$.

The United States, Europe, Turkey, Egypt and the United Arab Emirates are among the top suppliers of food and beverage products being sold through the retail grocery sector. Most retailers, because of historical or personal connections, tend to import from a single country/region. For example, Novis and Bambis prefer to import most of their food products from Europe. Shoa generally sources from the UAE, while Fantu imports a large portion of its food products from the United States. Nearly all of the processed and packaged foods sold at major retail outlets are imported. These products include the following: breakfast cereals, candy, cooking oils (e.g., soy, corn, sunflower and olive), rice, powdered milk, condiments (e.g., mustard, ketchup, and salad dressing), pastas, cookies and crackers, jams and jellies, and fruit juices. The combination of import duties and taxes processed grocery food items is quite high, with a cumulative tax burden of almost 65 percent. Specific duties and taxes on processed food items are as follows: import duty $(30 \%)$; VAT $(15 \%)$, surtax $(10 \%)$, and withholding tax $(3 \%)$. Thus, this study tries to make an investigation into the salesforce performance and salesforce job satisfaction in a country where more and more urban, middle -class consumers are turning to grocery stores, mini-marts, and neighborhood kiosks to satisfy some of the food and beverage demand.

\section{Research Questions}

Job satisfaction is a widely studied construct in marketing research on sales force (Brown \& Peterson, 1993), retail store managers (Lusch \& Serpkenci, 1990), and service workers (Boyt, Lusch, \& Naylor, 2001). This research examines the effects of antecedents of sales performance and in particular the mediating effect of sales performance on job satisfaction. Thus, the following research questions were raised.

- Can sales performance- be empirically verified by antecedent variables such as such ability, effort, self-efficacy, fixed compensation, job core characteristics?

- To what extent is salesforce performance export market performance influenced by deliberate marketing strategy implementation?

\section{Objective of the Study}

The objective of this study is to develop a model of work relationships and to investigate the relationship between salesperson performance and its key determinants, job characteristics, role perceptions, effort, ability, self-efficacy and job satisfaction.

\section{Scope of the Study}

This study is delimited to three major Ethiopian exporting companies engaged leather and leather products, textile and Garment products. The study units are all employees participating in formulating, implementing and monitoring, evaluating and control export marketing strategies. The major cities included Addis Ababa, Bahir Dar, Gondar, Hawassa, Nathreth and Dire Dawa. The variables under this study are delimited to ability, effort's, self -efficacy, fixed compensation, job core characters tics, role perceptions, salesforce performance and satisfaction. Methodologically, it is delimited to three major chain retail store companies exporting companies.

\section{Literature Review}

Advances in technology are not replacing the salesperson (Keenan, 1994); instead, the demand for salespeople has been increasing and continues to increase. Costs associated with salespeople recruiting, selection, and training keep soaring. Therefore, knowledge of how to achieve superior salesperson performance is of fundamental and enduring interest to sales managers and organizations, as well as salespeople themselves.

A salesforce control system is an organization's set of procedures for monitoring, directing, evaluating and compensating its employees (Anderson \& Oliver, 1987). It influences employee behavior in such a way that it enhances the welfare of both the firm and the employee. Salesforce control system are broadly classified into two categories, behavior based and outcome-based salesforce control system.

The importance of salesperson performance cannot be overstressed. The success of any sales and marketing organization ultimately depends on the success of individual salespeople, for their performance directly affects 
the firm's bottom line, not just in the short run, but in the long run as well. In the process of buyer-seller interaction and communication, salespeople develop new business, build customer trust, nurture long-term relationships, create added value for customers, and provide market information to management.

Sales person satisfaction is a widely studied construct in marketing research on sales force (Brown \& Peterson, 1993), retail store managers (Lusch \& Serpkenci, 1990), and service workers (Boyt, Lusch, \& Naylor, 2001). This research examines the antecedents of job performance and its effect on job satisfaction. However, findings in this literature about the relationships between job satisfaction and these antecedents have been inconsistent and even controversial. For example, despite the finding that people derive intrinsic value from work, the relationship between job performance and job satisfaction has been found to be inconsistent and weak (Iaffaldano \& Muchinsky, 1985). The existing job satisfaction research in marketing and organizational psychology is likely hampered by an omitted-variables bias and imprecise definitions of job performance. Nevertheless, results obtained by the authors who have studied the effect of effort show rather strong evidence of work effort as a direct antecedent of sales performance. Behrman \& Perreault (1984) found sales performance to be significantly related to the number of hours worked. In a study of 380 direct salespeople who worked for a national company that sells a durable product line door-to-door. Brown \& Peterson (1994) found a significant standardized path of .64 from work effort to sales performance.

\subsection{Effort and Job Performance}

Effort is an input to work, and job performance is an output from this effort. From a firm's perspective, effort and job performance may be difficult to distinguish, and effort is often inferred from the output produced. If effort is costly for an employee, it should have a negative, direct effect on job satisfaction. This implies that there is a conflict of interest between the employer, who wants the employee to work hard, and the employee, who wants the salary with the minimum possible effort. This conflict is the basis for the literature in economics on the relationship between principals and agents (Hart \& Holmstrom, 1987; Holmstrom, 1979). An employee will not be willing to exert effort unless he or she is paid, and the employer will not be willing to pay unless the employee works. A contract needs to be individually rational which implies that both parties must expect to be better off by engaging in the work relationship. However, few, if any, studies include the employee's effort as an antecedent of job satisfaction (Brown \& Peterson, 1994). Effort represents the force, energy, and/or activity by which work is accomplished, whereas motivation is the individual's psychological state with regard to choices involving the direction, intensity, and persistence of behavior (Ilgen \& Klein, 1988). Researchers have argued that effort should reflect both the duration of time spent in working and the intensity of work activities (Ilgen \& Klein, 1988). Effort is a mediating mechanism by which motivation is translated into accomplished work (Naylor et al., 1980). In other words, effort can be viewed as a natural outcome of one's motivational state and, in the meantime, a direct antecedent of work performance.

H1: A salesperson's work effort has a significant, positive effect his /her sales performance.

\subsection{Ability and Sales Performance}

Campbell \& Pritchard (1976), defined ability refers to an employee's skill and knowledge related to the specific duties of the job. This should also have a significant effect on observed job performance. For the highly competitive salespeople, the inherent desire to be number one and the importance they attach to exceeding the performance of others motivate them to exert a high effort level, set high goals, and use effective approaches (Bartkus et al., 1989).

H2: A salesperson's ability has a significant, positive effect his /her sales performance.

\subsection{Self-efficacy and Sales Performance}

Self-efficacy refers to people's judgments about their capability to organize and execute courses of action required to attain particular designated types of performance (Bandura, 1986). Social cognitive theory posits that an individual's self-efficacy belief in performing a particular task should predict the individual's actual level of performance. The theory further suggests that the effect of self-efficacy on task performance is primarily "through enlistment of effort and creative use of capabilities and resources" (Wood \& Bandura, 1989, p. 374). Despite this wide recognition of work effort as an important performance determinant, only scarce empirical attention has been devoted to the construct as a direct antecedent of performance.

H3: A salesperson's work effort has a significant, positive effect his /her sales performance.

\subsection{Compensation and Job Performance}

Agency theory makes a distinction between fixed compensation such as salary and variable compensation that 
depends on output including bonuses based on individual or firm performance. The agency theoretic prediction is that fixed compensation should have a significant effect on job satisfaction but not on effort, regardless of an employee's risk preference. For many firm's salesforce performance is a major determinant of company success. Several studies suggest that salesforce performance is affected not only by factors specific to the salesperson such as skill and aptitude, but also by the reward structure used by a company (Churchill, Ford, \& Walker, 1981). This reward structure has a direct effect on performance by providing the desired incentives for salespeople to work harder and more effectively, as well as an indirect effect through mediating variables such as satisfaction with the job. Lal Rajiv and Richard Staelin 1994, have investigated and hypothesized various factors to affect the form of the compensation plan defined in terms of salary and incentive pay and offer predictions about how the compensation plan changes with changes in these factors.

H3: Fixed compensation has a significant, positive effect on the salesperson's performance.

\subsection{Job's Core Characteristics and Sales Performance}

Job autonomy, job attractiveness, quality of supervisory feedback, social climate and compensation variables, represent the job's core characteristics (Fried \& Ferris, 1986). (Judge, Bono, \& Locke, 2000) defined Job autonomy, job attractiveness, quality of supervisory feedback, and social climate as follows: job autonomy as the degree to which the firm provides independence and discretion to the employee in fulfilling his or her role. $j o b$ attractiveness as the degree to which a job is exciting, challenging, and provides a sense of accomplishment. Supervisory feedback as the extent to which the employee receives information about his or her performance. Social climate as the degree to which there is a good working relationship among the employees within the company.

H4: Job's Core Characteristics has a significant and positive effect on salesperson performance.

\subsection{Role Perceptions and Job Performance}

Marketing researchers have shown significant interest in the constructs of role ambiguity and role conflict as they relate to salesforce outcomes. Several authors have addressed the psychometric qualities of the extant measures of these constructs. There are three role perception variables, role ambiguity, role conflict, and role overload. The Rizzo, House, \& Lirtzman (1970) defined role ambiguity, role conflict and role overload as follows: Role Ambiguity has been further defined as a combination of uncertainty about the relationship between action and output and a lack of clear directions and behavioral requirements from the supervisor. Role conflict has been defined as the congruency of various job responsibilities (i.e., the degree to which goals, objectives, and responsibilities of a position conflict with one another. Role conflict can arise from inconsistent demands from different role partners including supervisors, coworkers, customers) on the employee. Role overload is related with incongruences with personal values; conflicts among different roles; and conflicts among time, resources, and demands.

H5: Role Perceptions has a significant, negative effect on salespersons salesperson performance.

\subsection{Job Performance and Job Satisfaction}

Many studies treat effort as part of job performance, which is defined broadly as an aggregate construct of effort, skill, and outcomes that are important to the employee and outcomes that are important to the firm (Behrman \& Perreault, 1984; Walker, Churchill, \& Ford, 1977). Although the idea that an employee's job performance affects his or her job satisfaction is consistent with several psychological theories, such as intrinsic motivation theory (Deci \& Ryan, 1985), few studies have found support for it (Iaffaldano \& Muchinsky, 1985). Similarly, organizational studies of the sales force in marketing invariably find that the relationship between job performance and job satisfaction is weak As Brown \& Peterson (1993) Job performance is treated as an intermediate outcome variable (between antecedent variables and job satisfaction) in the study framework.

H6: A sales person's sales performance has a positive and significant effect on salesperson satisfaction.

\subsection{Antecedents of Job Performance and Job Satisfaction}

Locke (1967, p. 130) defined job satisfaction as "a pleasurable or positive emotional state," which is "a function of the perceived relationship between what one wants from a job and what one perceives it is offering." This assumption follows other "workplace studies" that have an economic orientation (Clark, 1997; Friedman, 1978). The literature suggests that the antecedents of job satisfaction can be categorized into personal characteristics, role perceptions, and organizational variables (Brown \& Peterson, 1993).

H7: Antecedents of sales performance has a significant and positive effect on sales persons satisfaction mediated by his or her salesperson performance. 


\section{Conceptual Framework of the Study}

In this research; ability, effort, self-efficacy, fixed corporation, job core observation, role perceptions are proposed to be related to salesforce performance and salespersons job satisfaction.

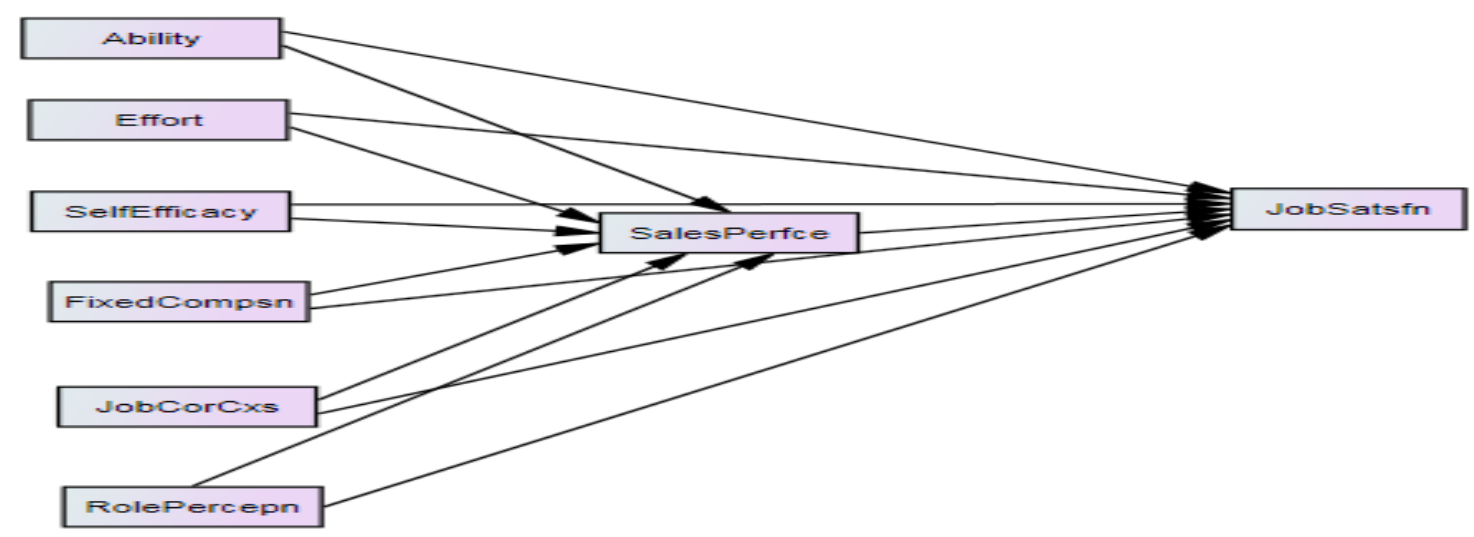

Figure 1. Conceptual framework of the study

Source: Modified from Brown \& Peterson (1993).

\section{Methodology}

\subsection{Sample}

The population of the study was top three chain retailers operating in Ethiopia. A cross-sectional research design was applied. A total of 384 respondents who are engaged in sales activities for at least 2 years were contacted to fill the questionnaires. A survey research method was applied as a means in the data collection process that involved structured questionnaires. The data collection process involved a strict follow up process to guarantee high response rate from the respondents who were filling in self-administered questionnaires.

This data set is based on a survey of a top three retail stores with more than 20 supermarkets. It contains typical measures collected for sales force performance and satisfaction studies and extensive operating and accounting information for each store. The stores are uniform in terms of merchandise and layout, and most stores have 1,500 to 5000 square meters of selling space. Retail Stores are about equally distributed over metropolitan and commercial cities of the country. Each store is staffed by a store manager and one or more assistant managers. A district supervisor monitors the operations of 5 to 10 stores and reports directly to senior management.

\subsection{Research Instrument}

The questionnaire was prepared following an exhaustive literature review and all constructs were measured with existing scales. The questionnaire consisted of questions related to the constructs and measures needed in the study. The final, refined instrument contained six groups of variables intended to measure ability, effort, self-efficacy, fixed compensation, job core characteristics, role perception, salesforce performance and salesforce job satisfaction. The six groups of explanatory variables were measured primarily by five-point Likert scales. All items were measured on a five-point Likert-type scale where $1=$ strongly disagree to $5=$ strongly agree.

\section{Result and discussion}

Mean score values, correlation and multiple regression analysis has been used to examine the model's fit.

\subsection{Demographic Profile}

A total of 450 questionnaires were distributed and 380 questionnaires were returned at the end of the data collection process, which gave the response rate of $84 \%$. The table found below shows general information of the respondents'. Information on the respondents' gender shows about 65.8 percent was male and 34.2 percent female. Respondent job level shows 47.4 percent were senior level sales person, 26.3 percent Junior level sales person, 15.8 percent Sales supervisor 5.3 sales manager, and the rest 5.3 percent were entry level sales person. Regarding to their work experience 73.7 percent were below 5 years and 26.3 percent were between 5 and 10 years. Annual sales of the firm that the respondents work about 55.3 percent were below. Birr 100,000,000 and 44.7 percent were above Birr 100,000,000. 
Table 1. General information of the study

\begin{tabular}{lllll}
\hline & & Frequency & Percent & Cumulative Percent \\
\hline Gender & Male & 250 & 65.8 & 65.8 \\
& Female & 130 & 34.2 & 100.0 \\
Job & Eotal & $\mathbf{3 8 0}$ & $\mathbf{1 0 0}$ & \\
& Entry level sales person & 20 & 5.3 & 5.3 \\
& Junior level sales person & 100 & 26.3 & 31.6 \\
& Senior level sales person & 180 & 47.4 & 78.9 \\
& Sales supervisor & 60 & 15.8 & 94.7 \\
& Sales manager & 20 & 5.3 & 100.0 \\
Experience & Total & $\mathbf{3 8 0}$ & $\mathbf{1 0 0}$ & \\
& 5 years & 280 & 73.7 & 73.7 \\
& 5-10 years & 100 & 26.3 & 100.0 \\
& Less 100,000 & 60 & 15.8 & 15.8 \\
& $100,001-500,000$ & 60 & 15.8 & 31.6 \\
& $1,000,000-10,000,000$ & 50 & 13.2 & 44.7 \\
& $10,000,001-100,000,000$ & 40 & 10.5 & 55.3 \\
& Above $100,000,000$ & 170 & 44.7 & 100 \\
\hline
\end{tabular}

\section{Reliability Test}

The Cronbach alpha value for the eight constructs has been computed: ability (0.574); effort $(0.530)$; self-efficacy (0.892); fixed compensation $(0.844)$; job autonomy $(0.787)$; supervisory feedback $(0.648)$; social climate (0.699); role ambiguity (0.734); role conflict $(0.688)$; role overload $(0.672)$; sales performance $(0.823)$; salesforce /job satisfaction (0.886) and all variables together gave a value of 0.824 Cronbach's alpha coefficients. So, in general all items of the variables are reliable since the collective alpha value are above the cutoff point .70 (Cronbach, 1951)

\section{Model Specification}

In its simplest form, regression analysis allows market researchers to analyze relationships between one independent and one dependent variable. In marketing applications, the dependent variable is usually the outcome we care about, while the independent variables are the instruments we have to achieve those outcomes with. It can also help make predictions (Mooi \& Sarstedt, 2011).

$$
\begin{aligned}
& \mathrm{Y}_{1}=a+b_{1} X_{1}+b_{2} X_{2}+b_{3} X_{3}+b_{4} X_{4}+\mathrm{e} \\
& Y_{2}=a+b_{5} X_{5}+\mathrm{e}
\end{aligned}
$$

\section{Where;}

$\mathrm{Y} 1$ is Sales performance

$\mathrm{Y} 2$ is Salesperson satisfaction

$\mathrm{X} 1$ is Ability

$\mathrm{X} 2$ is Effort

$\mathrm{X} 3$ is Job core characteristics

$\mathrm{X} 4$ is Role perception

$\mathrm{X} 5$ is Salesperson performance

\subsection{Correlations}

A correlation is a measure of how strongly two variables relate to each other. Correlation coefficients are frequently used to describe data because they are relatively easy to use and provide a great deal of information in just a single value (Mooi \& Sarstedt, 2011). Karl Pearson's coefficient of correlation or simple correlation is the most widely used Method of measuring the degree of relationship between two variables (Kotari, 2004). The calculated value of the correlation coefficient ranges from -1 to 1 , where -1 indicates a perfect negative relation (the relationship is perfectly linear) and 1 indicates a perfectly positive relationship. A correlation coefficient of 0 indicates that there is no correlation (Mooi \& Sarstedt, 2011). 
Table 2. Correlational matrix

\begin{tabular}{|c|c|c|c|c|c|c|c|c|c|}
\hline & & Ability & Effort & SelfEfficacy & FixedCompsn & JobCorCxs & RolePercepn & SalesPerfce & JobSatsfn \\
\hline \multirow[t]{2}{*}{ Ability } & Pearson & 1 & & & & & & & \\
\hline & Correlation & & & & & & & & \\
\hline \multirow[t]{3}{*}{ Effort } & Pearson & $.337^{* *}$ & 1 & & & & & & \\
\hline & Correlation & & & & & & & & \\
\hline & Sig. (2-tailed) & .000 & & & & & & & \\
\hline \multirow[t]{3}{*}{ SelfEfficacy } & Pearson & $.446^{* *}$ & $.405^{* *}$ & 1 & & & & & \\
\hline & Correlation & & & & & & & & \\
\hline & Sig. (2-tailed) & .000 & .000 & & & & & & \\
\hline \multirow[t]{3}{*}{ FixedCompsn } & Pearson & $.254^{* *}$ & $.163^{* *}$ & $.310^{* *}$ & 1 & & & & \\
\hline & Correlation & & & & & & & & \\
\hline & Sig. (2-tailed) & .000 & .001 & .000 & & & & & \\
\hline \multirow[t]{3}{*}{ JobCorCxs } & Pearson & $.505^{* *}$ & $.332^{* *}$ & $.307^{* *}$ & $.250^{* *}$ & 1 & & & \\
\hline & Correlation & & & & & & & & \\
\hline & Sig. (2-tailed) & .000 & .000 & .000 & .000 & & & & \\
\hline \multirow[t]{3}{*}{ RolePercepn } & Pearson & .057 & -.027 & -.056 & $.135^{* *}$ & $-.151^{* *}$ & 1 & & \\
\hline & Correlation & & & & & & & & \\
\hline & Sig. (2-tailed) & .271 & .599 & .272 & .008 & .003 & & & \\
\hline \multirow[t]{3}{*}{ SalesPerfce } & Pearson & $.493^{* *}$ & $.105^{*}$ & $.288^{* *}$ & -.012 & $.391^{* *}$ & .018 & 1 & \\
\hline & Correlation & & & & & & & & \\
\hline & Sig. (2-tailed) & .000 & .040 & .000 & .819 & .000 & .726 & & \\
\hline \multirow[t]{3}{*}{ JobSatsfn } & Pearson & $.428^{* *}$ & .013 & $.350^{* *}$ & $.343^{* *}$ & $.746^{* *}$ & -.039 & $.604^{* *}$ & 1 \\
\hline & Correlation & & & & & & & & \\
\hline & Sig. (2-tailed) & .000 & .807 & .000 & .000 & .000 & .449 & .000 & \\
\hline
\end{tabular}

**. Correlation is significant at the 0.01 level (2-tailed).

*. Correlation is significant at the 0.05 level (2-tailed). $\mathrm{N}=380$

Table 2 above shows the Pearson correlation result with its significant level. When we see the correlation of Ability, Effort, Self-Efficacy, and Job core characteristics with sales performance they have a significant Pearson correlation of $0.493,0.105,0.288$, and 0.391 respectively at 0.01 confidence interval. With regard to Job satisfaction variables: Ability, Self-Efficacy, Fixed compensation, and Job core characteristics have a Pearson Correlation of $.428, .350,343$, and.746 respectively at 0.01 confidence interval. From this result we can conclude that all the independent variables and dependent variables are significantly correlated.

\subsection{Regression}

In its simplest form, regression analysis allows market researchers to analyze relationships between one independent and one dependent variable. In marketing applications, the dependent variable is usually the outcome we care about, while the independent variables are the instruments we have to achieve those outcomes with. It can also help make predictions (Mooi \& Sarstedt, 2011).

\section{Determinants of Sales Performance}

The following tables are extracted from SPSS in order to perform a regression analysis between independent variables and dependent variable.

Table 3. Mode summary of sales performance and employees' sales performance

\begin{tabular}{|c|c|c|c|c|}
\hline \multicolumn{5}{|c|}{ Model Summary } \\
\hline Model & $\mathrm{R}$ & R Square & Adjusted R Square & Std. Error of the Estimate \\
\hline 1 & $.572^{\mathrm{a}}$ & .327 & .316 & .383 \\
\hline
\end{tabular}

The model for this regression was: $\mathbf{Y}_{1}=\boldsymbol{a}+\boldsymbol{b}_{1} \boldsymbol{X}_{1}+\boldsymbol{b}_{2} \boldsymbol{X}_{2}+\boldsymbol{b}_{3} \boldsymbol{X}_{3}+\boldsymbol{b}_{4} \boldsymbol{X}_{4}+\mathbf{e}$. From the model summary result we can see that independent variables explain the dependent variable with a percentage of 32.7. In cross-sectional designs, values of around 0.30 are common while for exploratory research, using cross-sectional data; values of 0.10 are typical (Mooi \& Sarstedt, 2011). 
Table 4. ANOVA

\begin{tabular}{lllllll}
\hline Model & & Sum of Squares & df & Mean Square & F & Sig. \\
\hline 1 & Regression & 26.536 & 6 & 4.423 & 30.166 & $.000^{\mathrm{b}}$ \\
& Residual & 54.686 & 373 & .147 & & \\
& Total & 81.221 & 379 & & & \\
\hline
\end{tabular}

a. Dependent Variable: SalesPerfce

b. Predictors: (Constant), RolePercepn, Effort, FixedCompsn, Ability, SelfEfficacy, JobCorCxs

The ANOVA tests the null hypothesis that multiple $\mathrm{R}$ in the population equals 0 . As can be seen from the ANOVA table, the independent variables significantly predict overall sales performance, $F=30.166, / \mathrm{p}<.000$.

Table 5. Coefficient table

\begin{tabular}{|c|c|c|c|c|c|c|}
\hline \multirow{2}{*}{\multicolumn{2}{|c|}{ Model }} & \multicolumn{2}{|c|}{ Unstandardized Coefficients } & \multirow{2}{*}{$\begin{array}{l}\text { Standardized Coefficients } \\
\text { Beta }\end{array}$} & \multirow[t]{2}{*}{$\mathrm{t}$} & \multirow[t]{2}{*}{ Sig. } \\
\hline & & $\mathrm{B}$ & Std. Error & & & \\
\hline \multirow[t]{7}{*}{1} & (Constant) & 1.198 & .295 & & 4.064 & .000 \\
\hline & Ability & .522 & .072 & .389 & 7.240 & .000 \\
\hline & Effort & -.168 & .058 & -.140 & -2.901 & .004 \\
\hline & SelfEfficacy & .150 & .048 & .162 & 3.151 & .002 \\
\hline & FixedCompsn & -.121 & .027 & -.210 & -4.552 & .000 \\
\hline & JobCorCxs & .243 & .050 & .254 & 4.887 & .000 \\
\hline & RolePercepn & .056 & .037 & .068 & 1.536 & .126 \\
\hline
\end{tabular}

Table 5 above shows the constant, beta, and significance level of each variable. It indicates that five variables which are Ability, Effort, Self-Efficacy, Fixed Compensation, and Job Core Characteristics influence sales performance significantly at $95 \%$ confidence interval with a sig. level of $0.000,0.004,0.002,0.000$, and 0.000 respectively. As the constant and $\mathrm{B}$ values are known the model will be: $\mathrm{Y}_{1}=\mathbf{1 . 1 9 8}+\mathbf{0 . 5 2 2 X _ { 1 } - 0 . 1 6 8 X _ { 2 } +}$ $0.243 X_{3}+0.056 X_{4}+0.05$

\section{Sales Performance and Job Satisfaction}

The following tables are extracted from SPSS in order to perform a regression analysis between independent variables and dependent variable.

Table 6. Model summary sales performance and job satisfaction

\begin{tabular}{lllll}
\hline Model & R & R Square & Adjusted R Square & Std. Error of the Estimate \\
\hline 1 & $.604^{\mathrm{a}}$ & .365 & .363 & .412 \\
\hline a. Predictors: (Constant), SalesPerfce & & \\
\hline
\end{tabular}

The model for this regression was: $\mathbf{Y}_{2}=\boldsymbol{a}+\boldsymbol{b}_{5} \boldsymbol{X}_{5}+\mathbf{e}$. From the model summary result in table 6 , we can see that independent variables explain the dependent variable with a percentage of $36.5 \%$. In cross-sectional designs, values of around 0.30 are common while for exploratory research, using cross-sectional data; values of 0.10 are typical (Mooi \& Sarstedt, 2011).

Table 7. ANOVA

\begin{tabular}{lllllll}
\hline Model & & Sum of Squares & df & Mean Square & F & Sig. \\
\hline 1 & Regression & 36.828 & 1 & 36.828 & 216.951 & $.000^{\mathrm{b}}$ \\
& Residual & 64.166 & 378 & .170 & & \\
& Total & 100.994 & 379 & & & \\
\hline \multicolumn{2}{l}{ a. Dependent Variable: JobSatsfn } & & & & \\
b. Predictors: (Constant), SalesPerfce & & & & \\
\hline
\end{tabular}

The ANOVA tests the null hypothesis that multiple $\mathrm{R}$ in the population equals 0 . As can be seen from the ANOVA table, the independent variables significantly predict overall Job Satisfaction, $F=216.951, / \mathrm{p}<.000$. 
Table 8. Coefficients

\begin{tabular}{|c|c|c|c|c|c|c|}
\hline \multicolumn{2}{|c|}{ Model } & \multicolumn{2}{|c|}{ Unstandardized Coefficients } & \multirow{2}{*}{$\begin{array}{l}\text { Standardized Coefficients } \\
\text { Beta }\end{array}$} & \multirow[t]{2}{*}{$\mathrm{t}$} & \multirow[t]{2}{*}{ Sig. } \\
\hline & & B & Std. Error & & & \\
\hline \multirow[t]{2}{*}{1} & (Constant) & 1.243 & .176 & & 7.046 & .000 \\
\hline & SalesPerfce & .673 & .046 & .604 & 14.729 & .000 \\
\hline
\end{tabular}

Table 8 above shows the constant, beta, and significance level of each variable. It indicates that six variables which are Ability, Effort, Self-Efficacy, Fixed Compensation, Job Core Characteristics, and sales performance influence job satisfaction significantly at $95 \%$ confidence interval with a sig. level of 0.000 for all variables. As the constant and $\mathrm{B}$ values are known the model will be: $\mathrm{Y}_{2}=1.243+0.673 X_{5}+0.05$

\subsection{AMOS Analysis for Mediation}

To identify the existence of mediation, a path diagram is drawn as a model for depicting a causal chain by using AMOS.

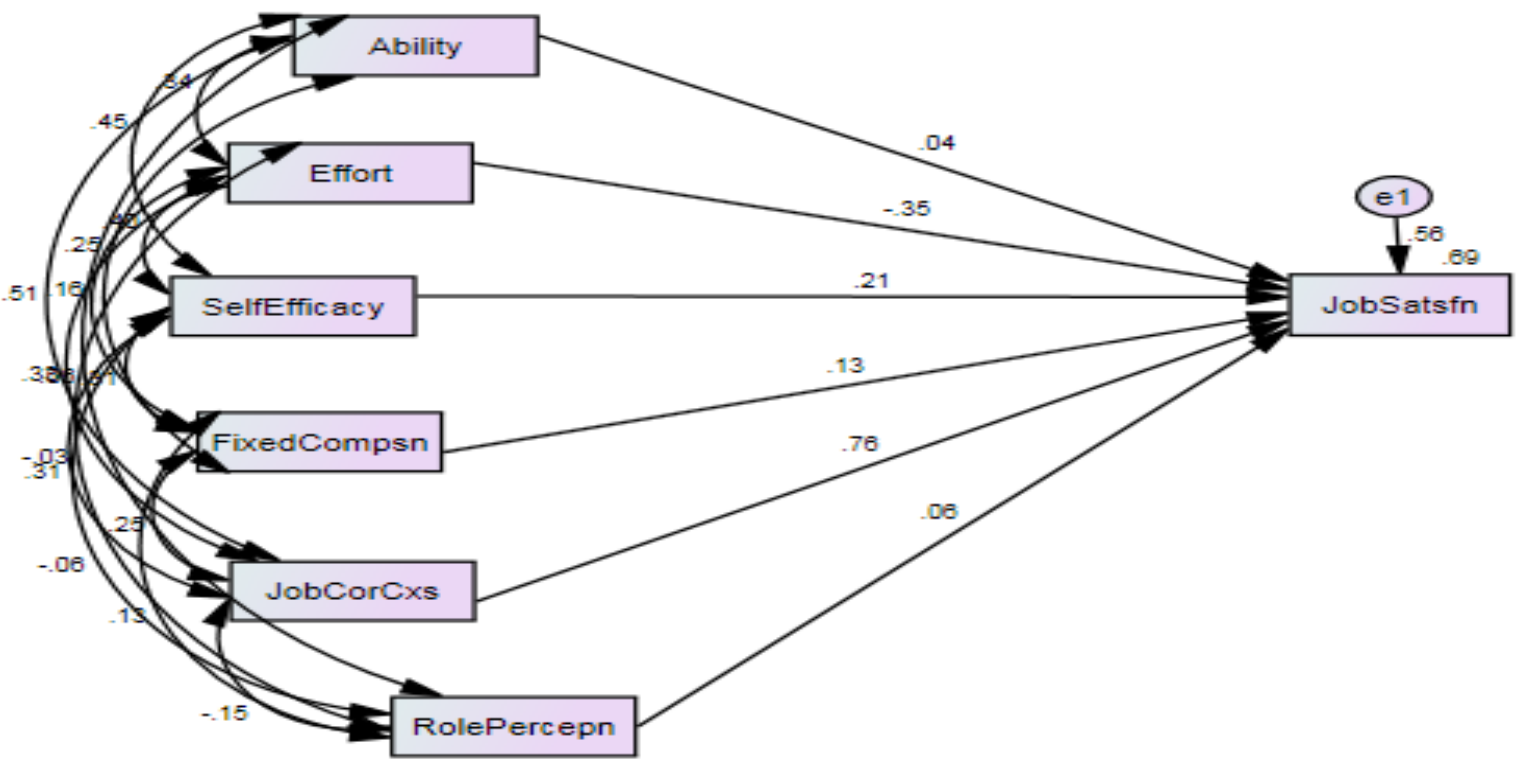

Figure 2. Direct effect of antecedent variables on job satisfaction

Table 9. Regression weights: (Group number 1 - Default model)

\begin{tabular}{lllllll}
\hline & & & Estimate & S.E. & C.R. & P \\
\hline JobSatsfn & $<---$ & SelfEfficacy & 0.216 & 0.036 & 6.050 & $* * *$ \\
JobSatsfn & $<--$ & Ability & 0.052 & 0.054 & 0.970 & 0.332 \\
JobSatsfn & $<---$ & Effort & -0.475 & 0.043 & -10.977 & $* * *$ \\
JobSatsfn & $<---$ & FixedCompsn & 0.083 & 0.020 & 4.175 & $* * *$ \\
JobSatsfn & $<---$ & JobCorCxs & 0.809 & 0.037 & 21.710 & $* * *$ \\
JobSatsfn & $<---$ & RolePercepn & 0.053 & 0.027 & 1.954 & 0.051 \\
\hline
\end{tabular}




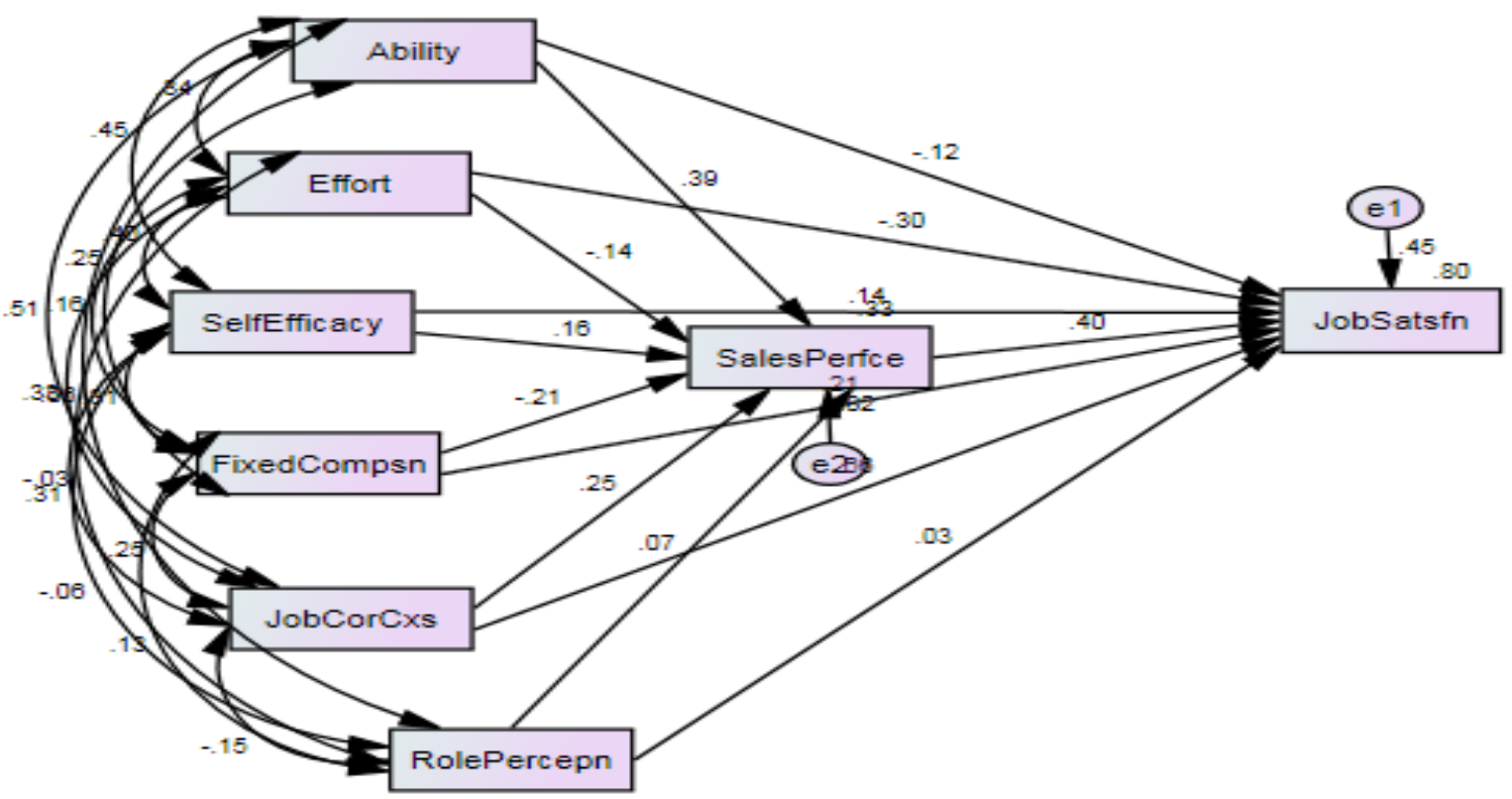

Figure 3. Direct and indirect effect of antecedent variables on mediating and outcome variables

Table 10. Regression weights: (Group number 1 - Default model)

\begin{tabular}{lllllll}
\hline & & & Estimate & S.E. & C.R. & P \\
\hline SalesPerfce & $<---$ & SelfEfficacy & 0.150 & 0.047 & 3.176 & 0.001 \\
SalesPerfce & $<---$ & FixedCompsn & -0.121 & 0.026 & -4.588 & $* * *$ \\
SalesPerfce & $<---$ & Effort & -0.168 & 0.057 & -2.924 & 0.003 \\
SalesPerfce & $<---$ & JobCorCxs & 0.243 & 0.049 & 4.927 & $* * *$ \\
SalesPerfce & $<---$ & RolePercepn & 0.056 & 0.036 & 1.548 & 0.122 \\
SalesPerfce & $<---$ & Ability & 0.522 & 0.071 & 7.298 & $* * *$ \\
JobSatsfn & $<---$ & SelfEfficacy & 0.149 & 0.029 & 5.104 & $* * *$ \\
JobSatsfn & $<---$ & Ability & -0.179 & 0.047 & -3.839 & $* * *$ \\
JobSatsfn & $<---$ & Effort & -0.400 & 0.035 & -11.315 & $* * *$ \\
JobSatsfn & $<---$ & FixedCompsn & 0.137 & 0.017 & 8.264 & $* * *$ \\
JobSatsfn & $<---$ & JobCorCxs & 0.702 & 0.031 & 22.541 & $* * *$ \\
JobSatsfn & $<---$ & RolePercepn & 0.029 & 0.022 & 1.287 & 0.198 \\
JobSatsfn & $<---$ & SalesPerfce & 0.444 & 0.031 & 14.133 & $* * *$ \\
\hline
\end{tabular}

Table 11. Direct and indirect effect of variables

\begin{tabular}{llll}
\hline & Indirect Effect & Direct Effect & Result \\
\hline SalesPerfce<--- SelfEfficacy & -0.0468 & 0.4 & Significant \\
JobSatsfn <--- Ability & 0.042 & 0.4 & Insignificant \\
JobSatsfn<--- Effort & 0.0224 & 0.4 & Significant \\
JobSatsfn<--- FixedCompsn & -0.1722 & 0.4 & Significant \\
JobSatsfn<--- JobCorCxs & 0.165 & 0.4 & Significant \\
JobSatsfn<--- RolePercepn & 0.0021 & 0.4 & Insignificant \\
\hline
\end{tabular}

From a theoretical perspective, a significant reduction on the path demonstrates that a given mediator is indeed potent. Perfect mediation holds, if the independent variable has no effect when the mediator is controlled (Reuben \& David, 1986).

Among the variables ability and role perception are not significantly influence employee's satisfaction and not mediated by sales person performance. The variable Job core characteristics has a significant influence on employee's satisfaction and partially mediated employee performance since its direct value dropped when the mediator variable removed from the model and the direct effect is still significant after mediator enters the model. For the rest variables which are; effort, self-efficacy, and fixed compensation no mediation is occurred. 


\subsection{Test Result of the Hypothesis}

Table 12. Hypothesis test results

\begin{tabular}{clll}
\hline S. No & Hypothesis & $\begin{array}{l}\text { Accept/ } \\
\text { Reject }\end{array}$ & Remark \\
\hline 1. & $\begin{array}{l}\text { H1: A salesperson's work effort has a significant } \\
\text { positive effect on his/her sales performance. }\end{array}$ & Rejected & $\begin{array}{l}\text { Salesperson's work effort has a significant effect on } \\
\text { his/her sales performance but the effect is negative. }\end{array}$ \\
2. $\begin{array}{l}\text { H2: A salesperson's ability has a significant positive } \\
\text { effect on his/her performance. }\end{array}$ & Accepted & \\
3. $\begin{array}{l}\text { H3: Fixed compensation has a significant, positive } \\
\text { effect on the salesperson's performance. }\end{array}$ & Accepted \\
4. $\begin{array}{l}\text { H4: Job's core characteristics has a significant and } \\
\text { positive effect on sales person performance. }\end{array}$ & Rejected & \\
5. $\begin{array}{l}\text { H5: Role perceptions has a significant negative effect } \\
\text { on salespersons performance. }\end{array}$ & Accepted & \\
6. $\begin{array}{l}\text { H6: A salesperson's sales performance has a positive } \\
\text { and significant effect on salesperson satisfaction. }\end{array}$ & Rejected & $\begin{array}{l}\text { Only one variable which is job core characteristics } \\
\text { partially mediated by salesperson performance. }\end{array}$ \\
7. $\begin{array}{l}\text { H7: Antecedents of sales performance has a significant } \\
\text { and positive effect on salesperson's satisfaction } \\
\text { mediated by his or salesperson performance. }\end{array}$ & & \\
\hline
\end{tabular}

\section{Conclusion}

The correlation of ability, effort, self-efficacy, and job core characteristics with sales performance they have a significant Pearson correlation of $0.493,0.105,0.288$, and 0.391 respectively at 0.01 confidence interval. With regard to salesforce satisfaction variables: Ability, Self-Efficacy, Fixed compensation, and Job core characteristics have a Pearson Correlation of $.428, .350,343$, and. 746 respectively at 0.01 confidence interval. The study indicates that five variables which are Ability, Effort, Self-Efficacy, Fixed Compensation, and Job Core Characteristics influence sales performance significantly at $95 \%$ confidence interval with a sig. level of $0.000,0.004,0.002,0.000$, and 0.000 respectively. The result of the study indicates that six variables which are Ability, Effort, Self-Efficacy, Fixed Compensation, Job Core Characteristics, and sales performance influence job satisfaction significantly at $95 \%$ confidence interval with a sig. level of 0.000 for all variables. Among the variables ability and role perception are not significantly influence employee's satisfaction and not mediated by sales person performance. The variable Job core characteristics has a significant influence on employee's satisfaction and partially mediated employee performance since its direct value dropped when the mediator variable removed from the model and the direct effect is still significant after mediator enters the model. For the rest variables which are; effort, self-efficacy, and fixed compensation no mediation has occurred.

\section{Implication of the Study and Future Area of Research}

This research contributes to the sales literature in several important ways. Firstly, it introduces the concept of key determinants of sales performance and offers a conceptualization of sales performance based on contemporary agency theory. Secondly, this study proposes and tests a model incorporating six antecedents to salesperson performance with a special focus on the mediating effect of sales performance on salesperson Job satisfaction. In testing the proposed model, a valid and reliable measurement instrument of key determinant of salesforce performance has been developed, which in turn will influence salespersons job performance. Additional variables may be incorporated to see the effect of antecedent variables on sales job satisfaction mediated by sales performance. Moreover, the effect of antecedent variables on sales performance mediated by job satisfaction can be further explored to inquire the relationship the other way around. Thirdly Personal factors (creativity, and selling experience, Trait Competitiveness) affecting sales performance can be further investigated. Research in different sectors may still produce contribution to the field.

\section{References}

Anderson, E., \& Richard, L. O. (1987). Perspective on Behavior-Based Versus Outcome-Based Sales Force Control Systems. Journal of Marketing, 51(October), 76-88. https://doi.org/10.2307/1251249

Bagozzi, R. P. (1978). Sales Force Performance and Satisfaction as a Function of Individual Difference, Interpersonal, and Situational Factors. Journal of Marketing Research, 15(November), 517-531. https://doi.org/10.2307/3150622 
Bagozzi, R. P. (1980). Performance and Satisfaction in an Industrial Sales Force: An Examination of their Antecedents and Simultaneity. Journal of Marketing, 44(Spring), 65-77. https://doi.org/10.2307/1249978

Bandura, A. (1986). Social Foundations of Thought and Action: A Social-Cognitive View. Englewood Cliffs, NJ: Prentice Hall.

Bartkus, K. R., Peterson, M. F., \& Bellenger, D. N. (1989). Type A Behavior, Experience, and Salesperson Performance. Journal of Personal Selling \& Sales Management, 9(Summer), 11-18.

Behrman, D. N., \& William, D. P. (1984). A Role Stress Model of the Performance and Satisfaction of Industrial Salespersons. Journal of Marketing, 48(Fall), 9-21. https://doi.org/10.2307/1251506

Boyt, T. E., Robert, F. L., \& Gillian, N. (2001). The Role of Professionalism in Determining Job Satisfaction in Professional Services. Journal of Service Research, 3(May), 321-330. https://doi.org/10.1177/109467050134005

Brown, S. P., \& Robert, A. P. (1993). Antecedents and Consequences of Salesperson Job Satisfaction: Meta-Analysis and Assessment of Causal Effects. Journal of Marketing Research, 30(February), 63-77. https://doi.org/10.2307/3172514

Brown, S. P., \& Robert, A. P. (1994). The Effect of Effort on Sales Performance and Job Satisfaction. Journal of Marketing, 58(April), 70-80. https://doi.org/10.2307/1252270

Campbell, J. P., \& Robert, D. P. (1976). Motivation Theory in Industrial and Organizational Psychology. In M. Dunnette (Ed.), Handbook of Industrial and Organizational Psychology (pp. 63-130). Chicago: Rand McNally.

Churchill, G. A., Neil, M. F., \& Orville, C. W. Jr. (1976). Organizational Climate and Job Satisfaction in the Salesforce. Journal of marketing Research, 13(November), 323-332. https://doi.org/10.2307/3151014

Churchill, G., Neil, F., \& Orville, W. (1981). Salesforce Management. Homewood: Richard Irwin Inc.

Clark, A. E. (1997). Job Satisfaction and Gender: Why Are Women So Happy at Work? Labour Economics, 4(4), 341-372. https://doi.org/10.1016/S0927-5371(97)00010-9

Cronbach, L. J. (1951). Coefficient Alpha and the Internal Structure of Tests. Psychometrika, 16, 297-334. https://doi.org/10.1007/BF02310555

Deci, E. L. (1971). Effects of Externally Mediated Rewards on Intrinsic Motivation. Journal of Personality and Social Psychology, 18(1), 105-115. https://doi.org/10.1037/h0030644

Deci, E. L., \& Richard, M. R. (1985). Intrinsic Motivation and Self- Determination in Human Behavior. New York: Plenum Press. https://doi.org/10.1007/978-1-4899-2271-7

Dunne, P., \& Robert, F. L. (1999). Retailing. Fort Worth, TX: Dryden Press.

Fried, Y., \& Gerald, R. F. (1986). The Dimensionality of Job Characteristics: Some Neglected Issues. Journal of Applied Psychology, 71(3), 419-426. https://doi.org/10.1037/0021-9010.71.3.419

Friedman, R. B. (1978). Job Satisfaction as an Economic Variable. American Economic Review, 68(May), 135-141.

Greene, W. H. (1991). Econometric Analysis. New York: Macmillan.

Hackman, J. R., \& Greg, R. O. (1975). Development of the Job Diagnostic Survey. Journal of Applied Psychology, 60(2), 159-170. https://doi.org/10.1037/h0076546

Hart, O. D., \& Bengt, H. (1987). The Theory of Contracts. In T. Bewley (Ed.), Advances in Economic Theory, Fifth World Congress. New York: Cambridge University Press. https://doi.org/10.1017/CCOL0521340446.003

Holmstrom, B. (1979). Moral Hazard and Observability. Bell Journal of Economics, 10(1), 74-91. https://doi.org/10.2307/3003320

Iaffaldano, M. T., \& Muchinsky, P. M. (1985). Job Satisfaction and Job Performance: A Meta-Analysis. Psychological Bulletin, 97(2), 251-273. https://doi.org/10.1037/0033-2909.97.2.251

Ilgen, D. R., \& Howard, J. K. (1988). Individual Motivation and Performance: Cognitive Influences on Effort and Choice. In J. P. Campbell \& R. J. Campbell (Eds.), Productivity in Organizations (pp. 143-176). San Francisco, CA: Jossey- Bass.

Judge, T. A., Joyce, E. B., \& Edwin, A. L. (2000). Personality and Job Satisfaction: The Mediating Role of Job 
Characteristics. Journal of Applied Psychology, 85(2), 237-249. https://doi.org/10.1037/0021-9010.85.2.237

Keenan, W. Jr. (1994). The Death of a Sales Manager. Sales and Marketing Management, 146, 67-74.

Kotari, C. R. (2004). Research Methodology: Methods and Techniques (2nd ed.). New Age International Publisher, India

Lal, R., Don, O., \& Richard, S. (1994). Salesforce Compensation Plans: An Empirical Test of the Agency Theory Framework. Marketing Letters, 5(2), 117-130. https://doi.org/10.1007/BF00994102

Lusch, R. F., \& Ray, R. S. (1990). Personal Differences, Job Tension, Job Outcomes, and Store Performance: A Study of Retail Store Managers. Journal of Marketing, 54(January), 85-101. https://doi.org/10.2307/1252175

Markus, C., Ganesh, I., \& Soberman, D. (2006). Job Satisfaction, Job Performance, and Effort: A Reexamination Using Agency Theory. Journal of Marketing, 70(January), 137-150

Mooi, E., \& Sarstedt, M. (2011). A Concise Guide to Market Research the Process, Data, and Methods Using IBM SPSS Statistics, Heidelberg, Germany. https://doi.org/10.1007/978-3-642-12541-6

Naylor, J. C., Pritchard, R. D., \& Ilgen, D. R. (1980). A Theory of Behavior in Organization's. New York: Academic Press.

Reuben, M., \& David, A. (1986). The Moderator-Mediator Variable Distinction in Social Psychological Research: Conceptual, Strategic, and Statistical Considerations. Journal of Personality and Social Psychology, 51(6), 1173-1182. American Psychological Association, Inc. https://doi.org/10.1037/0022-3514.51.6.1173

Rizzo, J. R., Robert, J. H., \& Sidney, I. L. (1970). Role Conflict and Ambiguity in Complex Organizations. Administrative Science Quarterly, 15(June), 150-163. https://doi.org/10.2307/2391486

Walker, O. C., Gilbert, A. C. Jr., \& Neil, M. F. (1977). Motivation and Performance in Industrial Selling: Present Knowledge and Needed Research. Journal of Marketing Research, 14(May), 156-168. https://doi.org/10.2307/3150465

Wood, R., \& Albert, B. (1989). Social Cognitive Theory of Organizational Management. Academy of Management Review, 14(3), 361-384.

\section{Copyrights}

Copyright for this article is retained by the author, with first publication rights granted to the journal.

This is an open-access article distributed under the terms and conditions of the Creative Commons Attribution license (http://creativecommons.org/licenses/by/4.0/). 